\title{
Expression of dipeptidyl peptidase-IV activity and/or structure homologs in human meningiomas
}

\author{
JARMILA STREMENOVÁ ${ }^{1}$, VLADISLAV MARES ${ }^{1}$, VERA LISÁ ${ }^{1}$, MAREK HILSER ${ }^{1}$, EVZEN KREPELA ${ }^{1}$, \\ ZDISLAVA VANICKOVÁ ${ }^{1}$, MARTIN SYRUCEK ${ }^{2}$, OLDRICH SOULA ${ }^{3}$ and ALEKSI SEDO ${ }^{1}$ \\ ${ }^{1}$ Joint Laboratory of Cancer Cell Biology of the Institute of Biochemistry and Experimental Oncology of the 1st Faculty \\ of Medicine, Charles University in Prague and the Institute of Physiology of Academy of Sciences of Czech Republic; \\ Departments of ${ }^{2}$ Pathology and ${ }^{3}$ Neurosurgery, Hospital Na Homolce, Prague, Czech Republic
}

Received September 16, 2009; Accepted November 13, 2009

DOI: 10.3892/ijo_00000506

\begin{abstract}
Meningiomas are tumors derived from arachnoid cap cells that represent $\sim 30 \%$ of all intracranial tumors. In this study, we investigated 22 human meningiomas for the expression of dipeptidyl peptidase (DPP)-IV activity and/or structure homologs (DASH), including canonical DPP-IV/ CD26, fibroblast activation protein- $\alpha($ FAP $\alpha)$, DPP8 and DPP9. DPP-IV-like enzymatic activity, including all enzymatically-active DASH molecules, was found in all 18 benign meningiomas WHO grade I and IV atypical meningiomas WHO grade II by continuous rate fluorimetric assay in tissue homogenates and catalytic enzyme histochemistry in situ. In atypical meningiomas, this activity was significantly higher and was associated with higher cell proliferation as detected by Ki67 antigen immunohistochemistry. The expression of DPP-IV/CD26 and FAP $\alpha$ demonstrated by real-time RT-PCR and immunohistochemistry was low. As shown histochemically, it occurred most often on the surface of fibrous bundles and whorls rich in extracellular matrix. Compared to DPP-IV/CD26 and FAP $\alpha$, the expression of DPP8 and DPP9 was higher and, in addition, it was present also in the cells inside these structures. Expression of CXCR4, the receptor of pro-proliferative chemokine stromal cell-derived factor- $1 \alpha$ (SDF-1 $\alpha$ ), DPP-IV substrate, was found in all tumors, suggesting higher values in atypical grade II samples. This is the first report on the expression status of dipeptidyl peptidase-IV and related molecules in meningiomas. It shows that DPP8 and DPP9 prevail over canonical DPP-IV/CD26 and FAP $\alpha$ in all examined patients. In addition, the study suggests an increase of DPP-IV-like enzymatic activity in these tumors of WHO grade II.
\end{abstract}

Correspondence to: Dr Aleksi Sedo, 1st Faculty of Medicine, Charles University in Prague, U Nemocnice 5, 128 53, Prague 2, Czech Republic

E-mail: aleksi@cesnet.cz

Key words: meningioma, dipeptidyl peptidase, DASH, CXCR4

\section{Introduction}

Meningiomas are the most common non-glial brain tumors originating from arachnoid cap cells of the brain and spinal cord leptomeninges. They account for $\sim 30 \%$ of all intracranial human tumors and are more common in older age and females. Among the wide variety of histological subtypes, meningothelial, fibrous and transitional meningiomas prevail. They are mostly benign WHO grade I or, more rarely, atypical WHO grade II or, exceptionally, most aggressive anaplastic WHO grade III tumors. Typical phenotypic markers of meningiomas are epithelial membrane antigen (EMA, MUC1), protein S-100, vimentin and cytokeratin although their expression has not been explicitly related to tumor malignancy (reviewed in refs. 1 and 2). Similarly to other neoplasms, growth of these tumors is influenced by several peptidases, such as matrix-metalloproteinases (3), cysteine proteinases, e.g. cathepsins (4) and/or serine proteases, e.g. urokinase-/tissue-plasminogen activators $(5,6)$, acting via cleavage of extra-cellular matrix proteins, which enhance migration and invasiveness of the tumor cells. Other peptidases, e.g. dipeptidyl peptidases, may, similarly to other tumor types, influence invasiveness and proliferation of the tumor cells via cleavage of a wide array of paracrine regulatory peptides and cytokines $(7,8)$.

Dipeptidyl peptidase-IV (DPP-IV/CD26, EC 3.4.14.5) is a serine protease identical with the lymphocyte differentiation antigen CD26 (9). It specifically splits off N-terminal dipeptides from peptide and protein substrates with the proline or alanine residues at the penultimate position $(10,11)$. Molecules displaying DPP-IV-like enzymatic activity and/or structural similarity to the canonical DPP-IV/CD26 have been grouped to a family of 'dipeptidyl peptidase-IV activity and/or structure homologs' (DASH) (12). The DASH group comprises enzymatically active members, including seprase fibroblast activation protein- $\alpha$ (FAP $\alpha)$, DPP-II/DPP7/ quiescent cell proline dipeptidase, DPP8, DPP9 and the enzymatically inactive members, such as DPP6 and DPP10.

Enzymatic activity of DASH molecules can modify signaling functions of a number of biological mediators, such as incretins (e.g. glucagone-like peptide-1 and gastric inhibitory polypeptide), neuropeptides (e.g. substance $\mathrm{P}$ and 
Table I. Primers and TaqMan probes used for the real-time RT-PCR quantitation of expression of the investigated transcripts.

\begin{tabular}{|c|c|c|}
\hline Transcript & $\begin{array}{c}\text { GeneBank } \\
\text { accession no. }\end{array}$ & Sequences and final concentration of primers and TaqMan probes \\
\hline DPP-IV & NM_001935 & $\begin{array}{ll}\text { Forward: } & \text { 5'-TGGAAGGTTCTTCTGGGACTG-3', } 200 \mathrm{nmol} / 1 \\
\text { Reverse: } & \text { 5'-GATAGAATGTCCAAACTCATCAAATGT-3', } 200 \mathrm{nmol} / 1 \\
\text { TaqMan probe: 5'-(6-FAM)CACCGTGCCCGTGGTTCTGCT(TAMRA)-3', } 200 \mathrm{nmol} / 1\end{array}$ \\
\hline $\mathrm{FAP} \alpha$ & NM_004460 & $\begin{array}{ll}\text { Forward: } & \text { 5'-TGCCACCTCTGCTGTGC-3', } 200 \mathrm{nmol} / 1 \\
\text { Reverse: } & \text { 5'-GAAGCATTCACACTTTTCATGGT-3', } 200 \mathrm{nmol} / 1 \\
\text { TaqMan probe: } & \text { 5'-(6-FAM)TGCATTGTCTTACGCCCTTCAAGAGTTC (TAMRA)-3', } \\
& 200 \mathrm{nmol} / 1\end{array}$ \\
\hline DPP8 & $\begin{array}{l}\text { NM_130434 } \\
\text { NM_197960 }\end{array}$ & $\begin{array}{ll}\text { Forward: } & \text { 5'-CCTGTCACCGAGGGCTTAA-3', } 400 \mathrm{nM} \\
\text { Reverse: } & \text { 5'-AACCCTGAAGATATCTGACCTCTG-3', } 400 \mathrm{nM} \\
\text { TaqMan probe: 5'-(6-FAM)CAGGTGGAAGGACTCCAATATCTAGCTTCTCG } & \\
& \text { (TAMRA)-3', } 200 \mathrm{nM}\end{array}$ \\
\hline DPP9 & NM_139159 & $\begin{array}{ll}\text { Forward: } & \text { 5'-GGTGGAGATCGAGGACCAG-3', } 400 \mathrm{nM} \\
\text { Reverse: } & \text { 5'-TGGCCACCTTGAACACCT-3', } 400 \mathrm{nM} \\
\text { TaqMan probe: } 5 \text { '-(6-FAM)AAGCCATACTTCTCGGCCACGAACTG (TAMRA)-3', } 200 \mathrm{nM}\end{array}$ \\
\hline CXCR4 & NM_001008540 & $\begin{array}{ll}\text { Forward: } & \text { 5'-CATGGGTTACCAGAAGAAACTGA-3', } 400 \mathrm{nmol} / \mathrm{l} \\
\text { Reverse: } & \text { 5'-GACTGCCTTGCATAGGAAGTTC-3', } 400 \mathrm{nmol} / \mathrm{l} \\
\text { TaqMan probe: 5'-(6-FAM)CACCTGTCAGTGGCCGACCTCCT (TAMRA)-3', } 200 \mathrm{nmol} / \mathrm{l}\end{array}$ \\
\hline ß-actin & NM_001101 & $\begin{array}{ll}\text { Forward: } & \text { 5'-CTGGCACCCAGCACAATG-3', } 200 \mathrm{nmol} / 1 \\
\text { Reverse: } & \text { 5'-GGGCCGGACTCGTCATAC-3', } 200 \mathrm{nmol} / \mathrm{l} \\
\text { TaqMan probe: 5'-(VIC)AGCCGCCGATCCACACGGAGT (TAMRA)-3', } 200 \mathrm{nmol} / 1\end{array}$ \\
\hline
\end{tabular}

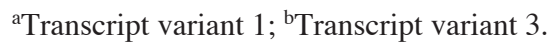

neuropeptide $\mathrm{Y}$ ) and chemokines, e.g. eotaxin and stromal cell-derived factor- $1 \alpha(\mathrm{SDF}-1 \alpha)$. Their cleavage can lead to their inactivation or changes their receptor-binding preference resulting in different functional effects. Therefore, DASH may exhibit multiple, although not yet enough elucidated functions controlling tumor growth as well as other pathophysiological processes (8).

The present study is the first analysis of the expression pattern of DASH molecules in human meningiomas. Additionally, since SDF-1 $\alpha$ is a substrate of DPP-IV-like enzymatic activity and has a pro-proliferative effect on meningothelial cells in vitro (13), expression of its receptor CXCR4 was determined in meningiomas in situ.

\section{Materials and methods}

Patients, sample preparation and histological characterization. Tumor specimens were collected from 22 patients (20 female and 2 male) undergoing brain tumor resection (18 benign meningiomas and 4 atypical meningiomas) at the Department of Neurosurgery, Hospital Na Homolce, Prague. Written informed consent was obtained from all patients entering this study, according to the guidelines of the Institutional Ethics Committee. Tissue samples, clear of macroscopic vessels and necrotic segments having the fresh wet weight of $\sim 80-150 \mathrm{mg}$, were frozen on solid $\mathrm{CO}_{2}$ and were stored at $-80^{\circ} \mathrm{C}$. Vascularisation and necrotic areas were scored microscopically on a 4-tiered scale (0 to 3 crosses).

Isolation and quantification of total RNA, real-time RT-PCR. Total RNA was isolated using the TRIzol Reagent (Invitrogen, UK). The concentration of total RNA was determined using the RiboGreen RNA Quantitation Kit (Molecular Probes, USA). The expression of DPPIV, FAP $\alpha$, CXCR4, DPP8 (variants 1 and 3) and DPP9 mRNAs (target transcripts) and (ß-actin mRNA (internal reference transcript) was quantified by a coupled real-time RT-PCR assay on the ABI PRISM 7700 Sequence Detection System (Applied Biosystems, USA) as described previously (14). The gene coding region-specific oligonucleotide primers and fluorogenic TaqMan probes for the coupled real-time RT-PCR assay were designed with the program Primer Express (Applied Biosystems) and were synthesized at Proligo (France) and Applied Biosystems (UK), respectively (Table I).

The statistical difference of the $B$-actin mRNA-normalized target transcript expression in tumor and normal tissues was calculated from the linearized $\Delta \mathrm{CT}$ data (i.e. $2^{-\Delta \mathrm{CT}}$ ) and the tumor/normal ratio of the $\beta$-actin mRNA-normalized target transcript expression was calculated by means of the $2^{-\Delta \Delta \mathrm{CT}}$ method (15). 
Table II. Characterization of the experimental cohort.

\begin{tabular}{llllll}
\hline Diagnosis & $\begin{array}{c}\text { Gender } \\
\text { female/male }\end{array}$ & Age & p53 & Ki67 & Vascularisation Necrosis \\
\hline
\end{tabular}

\begin{tabular}{|c|c|c|c|c|c|c|}
\hline \multicolumn{7}{|c|}{ Meningiomas WHO grade I } \\
\hline Transitional & $10 / 0$ & $55(36-66)$ & $27.2 \%(0-75 \%)$ & $3.0 \%(1-5 \%)$ & $0.15(0-1)$ & 0 \\
\hline Fibrous & $3 / 0$ & $54(47-64)$ & $8.7 \%(0-25 \%)$ & $1.7 \%(1-2 \%)$ & 0 & $0.33(0-1)$ \\
\hline Angiomatous & $1 / 1$ & $49(46-52)$ & $23.5 \%(2-45 \%)$ & $3 \%(1-5 \%)$ & $1.75(1.5-2)$ & 0 \\
\hline Microcystic & $1 / 0$ & 59 & $40 \%$ & $5 \%$ & 0 & 0 \\
\hline Meningothelial & $1 / 0$ & 79 & $30 \%$ & $2 \%$ & 1 & 0 \\
\hline Psammomatous & $1 / 0$ & 78 & $0 \%$ & $1 \%$ & 0 & 0 \\
\hline \multicolumn{7}{|c|}{ Meningiomas WHO grade II } \\
\hline Atypical & $3 / 1$ & $51(37-71)$ & $33.8 \%(5-80 \%)$ & $7.8 \%(3-12 \%)$ & $0.75(0-1)$ & $0.25(0-1)$ \\
\hline
\end{tabular}

Values are presented as the mean; the ranges of values are shown in the brackets. Vascularisation and necrosis were scored on a 4-tiered scale (0 to 3 crosses).

DPP-IV-like enzymatic activity biochemical assay and total protein determination. Tissue samples were homogenized in ice-cold $25 \mathrm{mM}$ phosphate-buffered saline (PBS, $2.0 \mathrm{mM}$ $\left.\mathrm{Na}_{2} \mathrm{HPO}_{4}, 0.6 \mathrm{mM} \mathrm{KH} \mathrm{PO}_{4}, 22.4 \mathrm{mM} \mathrm{NaCl}\right) \mathrm{pH}$ 6.0, with an Ultra-Turrax homogenizer fitted with a $\mathrm{S} 8 \mathrm{~N}-5 \mathrm{G}$ probe (IKA, Germany) and the tissue homogenates were used for the enzyme activity assay immediately.

The DPP-IV-like and DPP-II-like enzymatic activities were determined by continuous rate fluorimetric assay at $37^{\circ} \mathrm{C}$ in PBS buffer (137 mM NaCl, $4 \mathrm{mM} \mathrm{Na}_{2} \mathrm{HPO}_{4}, 2.68 \mathrm{mM}$ $\left.\mathrm{KCl}, 1.76 \mathrm{mM} \mathrm{KH}_{2} \mathrm{PO}_{4}\right), \mathrm{pH} 7.4$, and $0.1 \mathrm{M}$ citric acid/0.2 M $\mathrm{Na}_{2} \mathrm{HPO}_{4}$ buffer, $\mathrm{pH} 5.5$, respectively, and with $50 \mu \mathrm{mol} / 1$ of H-7-(glycyl-L-prolyl-amido)-4-methylcoumarin (Gly-ProAMC) and $50 \mu \mathrm{mol} / 1$ of H-7-( $L$-lysyl- $L$-alanyl-amido)-4methylcoumarin (Lys-Ala-AMC) as substrates (both from Bachem, Switzerland), respectively (16). The release of 7-amino-4-methylcoumarin was monitored at the excitation and emission wavelengths of 380 and $460 \mathrm{~nm}$, respectively.

Based on the enzymatic activity histogram, samples were categorized to 3-tiered scale: low $=0-4$ arbitrary units, with the median of 3.22 ; medium $=4-8$ arbitrary units, with the median of 6.10 and high $=8-17$ arbitrary units, with the median of 11.20.

Total protein concentration in tissue homogenates was determined colorimetrically according to the Lowry procedure (17) using bovine serum albumin as a standard.

DPP-IV-like catalytic enzyme histochemistry. Histochemical demonstration of DPP-IV-like catalytic activity in situ was performed according to Lojda (18) in $10 \mu \mathrm{m}$ cryostat tissue sections cut at $-20^{\circ} \mathrm{C}$ (Bright Instrument Company Ltd., UK). The sections were fixed in a 1:1 mixture of acetone and chloroform for $2 \mathrm{~min}$ at $4^{\circ} \mathrm{C}$ and were incubated with $830 \mu \mathrm{M}$ of H-7-(glycyl- $L$-prolyl-amido)-4-methoxy-2-naphthylamide as a substrate (Bachem, Switzerland) and Fast Blue B as a coupler of the enzymatically released 4-methoxy-2-naphthylamine, in PBS pH 7.4, at $4^{\circ} \mathrm{C}$. In controls, the DPP-IV substrate was omitted from the incubation medium. The staining intensity was scored on a 4 -tiered scale (low $=1$; medium $=2$, high $=3,0=$ control reaction without the enzyme substrate), averaged from 8-10 fields, observed at a magnification of 400-fold in several non-consecutive tissue sections.

Immunohistochemistry. Immunodetection of DPP-IV, FAP $\alpha$, DPP8, DPP9 and CXCR4 was performed in $10 \mu \mathrm{m}$ cryostat tissue sections preincubated in $3 \%$ of heat-inactivated bovine fetal serum for $20 \mathrm{~min}$, followed by overnight incubation with the respective primary antibodies at $4^{\circ} \mathrm{C}$ : mouse monoclonal anti-human DPP-IV (1:100, clone M-A261, Acris, Germany), mouse monoclonal anti-human FAP $\alpha$ (1:200, clone F11-24, Alexis Biochemical, USA), rabbit polyclonal anti-human DPP8 and anti-human DPP9 (1:150, Abcam, UK) and rabbit polyclonal anti-human CXCR4 (1:200, Acris, Germany). This was followed by incubation with anti-mouse- or anti-rabbit-IgG-FITC conjugates (1:200, Sigma, USA) or anti-mouse-IgG-AlexaFluor 488 conjugate (1:1000, Invitrogen, USA). In staining controls, the primary antibodies were omitted. Staining intensity was scored using the above-mentioned 4-tiered scale. The proliferation activity was analyzed in situ by immunohistochemical staining of Ki67 antigen expression, using a mouse monoclonal antihuman Ki67 antibody (clone MIB-1, Dako, Denmark). The in situ expression of p53 protein was examined using immunostaining with a mouse monoclonal anti-human p53 antibody (clone DO-7; Dako).

Statistical analysis. Statistica 8.0 software was used. Differences between groups were evaluated with Kruskal-Wallis test or Mann-Whitney test; correlations were analyzed by means of Spearman correlation coefficient.

\section{Results}

General characteristics of tumor samples. As shown in Table II, the studied set of patients consisted of 18 patients with benign meningiomas WHO grade I (including 6 histological subtype groups), and 4 patients with atypical meningiomas WHO grade II. The age range was 36-79 years, with 

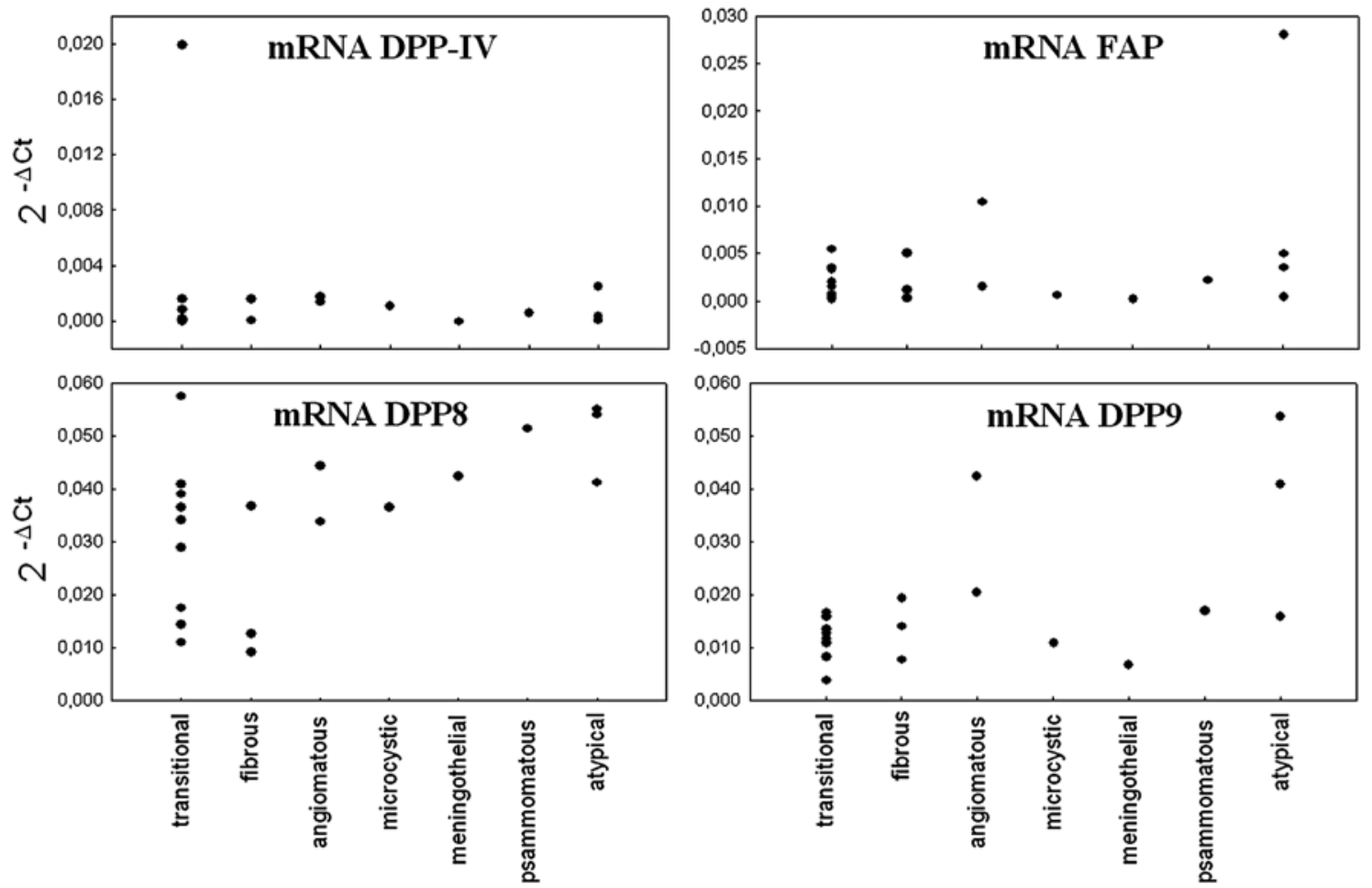

Figure 1. The mRNA expression of DPP-IV/CD26, FAP $\alpha$, DPP8 and DPP9 determined by real-time RT-PCR normalized to human $\beta$-actin in various histological types of meningiomas WHO grade I and II.

an average of 61 years $(\mathrm{SD} \pm 12)$. In this group of meningioma patients, there were 20 women and 2 men. As assessed by Ki67 immunostaining, the proliferation activity in tissue sections ranged from 1 to $12 \%$, with prevalence in atypical meningiomas. The immunoexpression of p53 protein in tissue sections varied from 0 to $80 \%$, without an evident relationship to WHO grade. Vascularisation was, except in 2 transitional, 2 angiomatous, 1 meningothelial and 3 atypical meningiomas, very low. All tumors were free of necrosis, except 1 fibrous and 1 atypical meningioma.

DASH mRNA expression. As shown by real-time RT-PCR (Fig. 1), DPP-IV, FAP $\alpha$, DPP8 and DPP9 mRNAs were expressed in all analyzed tumor samples. The expression level of individual DASH molecules varied among individual types of tumors. Compared to DPP-IV/CD26 and FAP $\alpha$ mRNA expression, the scatter of DPP8 and DPP9 values was relatively broader. There was statistically significant difference in DPP8 mRNA expression between benign meningiomas grade I and atypical meningiomas grade II $(\mathrm{p}=0.039)$. However, no statistical significance occurred in any DASH mRNA expression between individual histological tumor subtypes $(\mathrm{p}>0.05)$.

The expression of DPP-IV/CD26 mRNA showed a positive correlation with FAP $\alpha$ mRNA expression in all examined samples $(\mathrm{R}=0.672, \mathrm{p}=0.001)$.

DPP-IV-like enzymatic activity determined biochemically and histochemically

Biochemical approach. Most benign meningiomas grade I exhibited medium (14 of 18 samples, 78\%) and high (2 of 18 samples, $11 \%$ ) DPP-IV-like enzymatic activity measured by fluorimetric assay using Gly-Pro-AMC as a substrate. Low enzymatic activity occurred only in 2 of 18 benign samples (11\%). In the atypical meningioma variants grade II, all samples had high or medium activity (4 of 4 samples, $100 \%$, Table III). Moreover, in the WHO grade II group, there was statistically significant higher activity than in WHO grade I group ( $\mathrm{p}=0.011$, Fig. 2).

The enzymatic activity of tissue homogenates measured at the acidic pH 5.5 using Lys-Ala-AMC as a substrate, was only slightly above detection limit (mean $0.74 \pm$ SD 0.31 arbitrary units). This suggests that DPP-II does not significantly contribute to the overall DPP-IV-like enzymatic activity (data not shown).

In addition, higher DPP-IV-like enzymatic activity was accompanied by higher intensity of proliferation activity as detected by Ki67 immunohistochemistry (Fig. 3; Spearman correlation coefficient $\mathrm{R}=0.553, \mathrm{p}=0.008$ ). Furthermore, the proliferation activity was higher in atypical meningiomas grade II compared to the benign ones $(\mathrm{p}=0.014)$.

Catalytic enzyme histochemistry. Similarly to biochemical data, the DPP-IV-like enzymatic activity was revealed in all examined samples. Medium or high activity occurred in 17 of $22(77 \%)$ meningiomas, irrespective of the tumor grade (Table III). The enzymatic activity greatly varied both in the group of patients as well as in the individual tumors. The stained cells occurred either solitary or in the nests of different size and irregular shape scattered throughout specimens. As evident in samples with low DPP-IV-like activity staining, the enzymatic activity occurred primarily in the perivascular cell compartment, from where stained cells were spreading to the surrounding parenchyma (Fig. 4E and F). In 
Table III. Number of meningioma samples with DPP-IV-like enzymatic activity, DPP-IV, FAP $\alpha$, DPP8, DPP9 and CXCR4 receptor expression detected biochemically and histochemically.

\begin{tabular}{|c|c|c|c|c|c|c|c|c|}
\hline \multirow[b]{2}{*}{$\begin{array}{l}\text { Low/medium/high } \\
\text { Diagnosis }\end{array}$} & \multirow[b]{2}{*}{$\begin{array}{l}\text { No. of } \\
\text { cases }\end{array}$} & \multicolumn{2}{|c|}{ Enzymatic activity } & \multicolumn{5}{|c|}{ Immunohistochemistry } \\
\hline & & $\begin{array}{l}\text { Biochemical } \\
\text { assay }\end{array}$ & $\begin{array}{c}\text { Catalytic } \\
\text { histochemistry }\end{array}$ & $\begin{array}{l}\text { DPP-IV/ } \\
\text { CD26 }\end{array}$ & FAP $\alpha$ & DPP8 & DPP9 & CXCR4 \\
\hline \multicolumn{9}{|c|}{ Meningiomas WHO grade I } \\
\hline Transitional & 10 & $1 / 7 / 2$ & $1 / 5 / 4$ & $4 / 5 / 1$ & $10 / 0 / 0$ & $1 / 3 / 6$ & $2 / 5 / 3$ & $7 / 2 / 1$ \\
\hline Fibrous & 3 & $0 / 3 / 0$ & $1 / 1 / 1$ & $3 / 0 / 0$ & $3 / 0 / 0$ & $0 / 3 / 0$ & $2 / 1 / 0$ & $3 / 0 / 0$ \\
\hline Angiomatous & 2 & $1 / 1 / 0$ & $1 / 1 / 0$ & $2 / 0 / 0$ & $2 / 0 / 0$ & $0 / 1 / 1$ & $0 / 2 / 0$ & $2 / 0 / 0$ \\
\hline Microcystic & 1 & $0 / 1 / 0$ & $0 / 0 / 1$ & $0 / 1 / 0$ & $1 / 0 / 0$ & $0 / 0 / 1$ & $0 / 1 / 0$ & $1 / 0 / 0$ \\
\hline Meningothelial & 1 & $0 / 1 / 0$ & $0 / 1 / 0$ & $1 / 0 / 0$ & $1 / 0 / 0$ & $0 / 0 / 1$ & $0 / 0 / 1$ & $0 / 0 / 1$ \\
\hline Psammomatous & 1 & $0 / 1 / 0$ & $1 / 0 / 0$ & $1 / 0 / 0$ & $1 / 0 / 0$ & $0 / 0 / 1$ & $0 / 1 / 0$ & $1 / 0 / 0$ \\
\hline All subtypes & 18 & $2 / 14 / 2$ & $4 / 8 / 6$ & $11 / 6 / 1$ & $18 / 0 / 0$ & $1 / 7 / 10$ & $4 / 10 / 4$ & $14 / 2 / 2$ \\
\hline \multicolumn{9}{|c|}{ Meningiomas WHO grade II } \\
\hline Atypical & 4 & $0 / 1 / 3$ & $1 / 2 / 1$ & $4 / 0 / 0$ & $4 / 0 / 0$ & $0 / 2 / 2$ & $0 / 3 / 1$ & $2 / 1 / 1$ \\
\hline
\end{tabular}

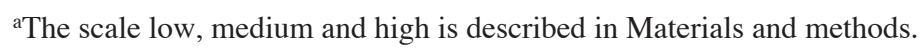

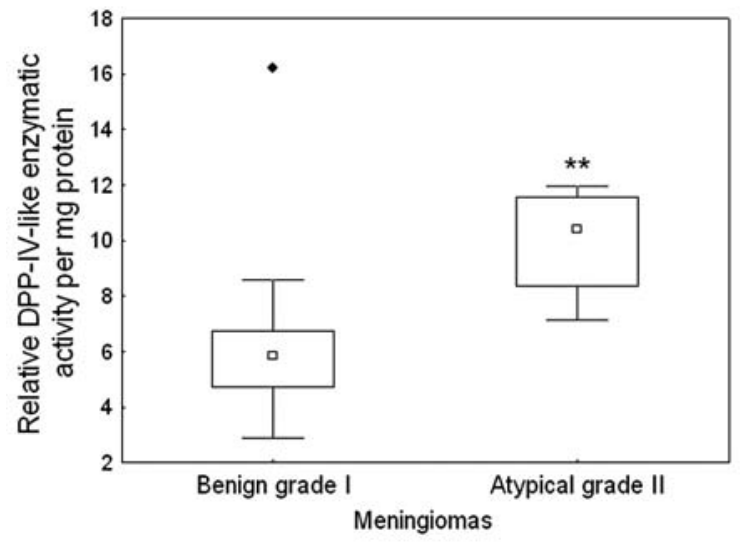

Figure 2. Specific DPP-IV-like enzymatic activity determined in human meningiomas. Squares, medians; boxes, middle $25-75 \%$ of the measured values; bars, minimal and maximal values; $\bullet$ extreme value; ${ }^{* *} \mathrm{p}=0.011$; spearman correlation.

fibrous and transitional meningioma subtypes, the enzymatic activity-bearing cells trimmed fibrous bundles rich in extracellular matrix at their surface or also inside their interior (Fig. 4H). Positive staining also appeared at the surface of outermost as well as deeper whorl lamellas (Fig. 4G, insert).

DASH protein immunoexpression pattern. DPP-IV/CD26 immunopositivity was low in most benign grade I (11 of 18 patients, 61\%) and all atypical grade II meningiomas (4 of 4 patients, $100 \%)$. Medium or high DPP-IV/CD26 immunoexpression appeared in 7 of $18(39 \%)$ benign meningiomas (Table III). The immunostaining usually trimmed the surface of fibrous bundles and whorls, where it was often present only in the cells of the outermost lamellas (Fig. 4I and J, insert). In samples with very low positivity only a few solitary cells were stained.

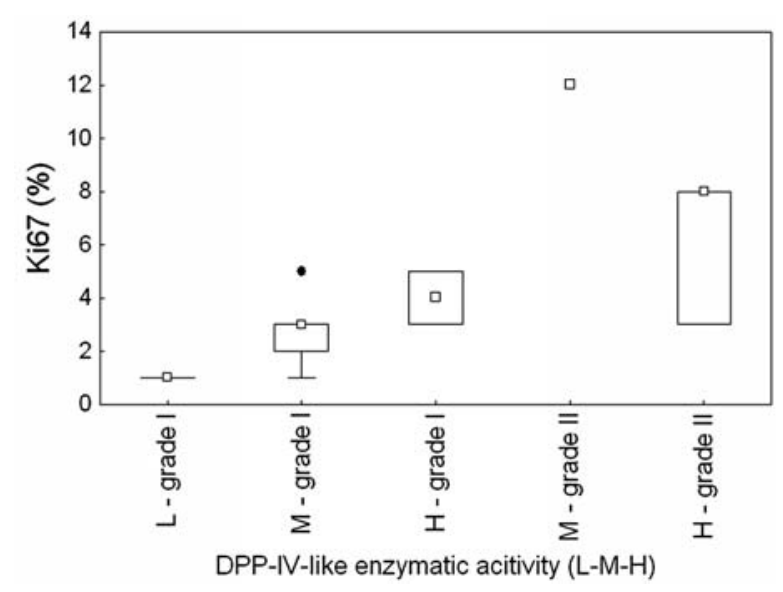

Figure 3. Relation of proliferation activity and DPP-IV-like enzymatic activity in meningiomas WHO grade I and WHO grade II. L, low; M, medium; $\mathrm{H}$, high activity subgroups classified as described in Materials and methods; squares, medians; boxes, middle $25-75 \%$ of measured values; bars, minimal resp.; maximal values; $\bullet$, remote values.

The immunohistochemical expression of FAP $\alpha$ (Fig. 4K and L) was low in all examined meningiomas (Table III). The tissue localization was similar to the DPP-IV/CD26 expression.

On the other hand, the immunoexpression of DPP8 was high or medium in 21 of $22(95 \%)$ examined meningioma patients (Table III, Fig. $4 \mathrm{M}$ and N). The immunostaining of DPP9 was similar, although its intensity was lower; it was high or medium in 18 of $22(82 \%)$ meningioma patients (Table III, Fig. 4O and P). The staining tissue distribution of both these peptidases was similar to the total DPP-IV-like activity. It occurred in flat meningocytes over the fibrous bundles and the whorl lamellas as well as patches scatterd in the interspaced parenchyma (Fig. 4M-P). 

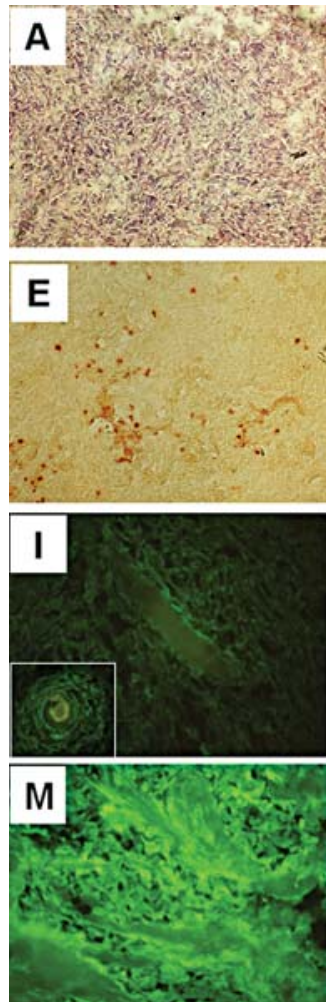
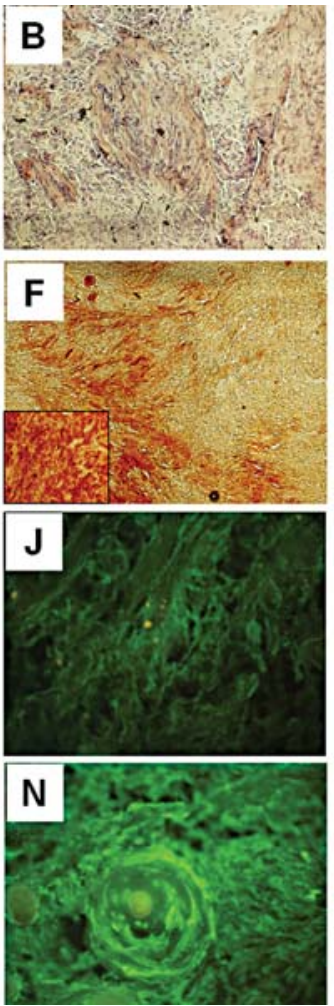
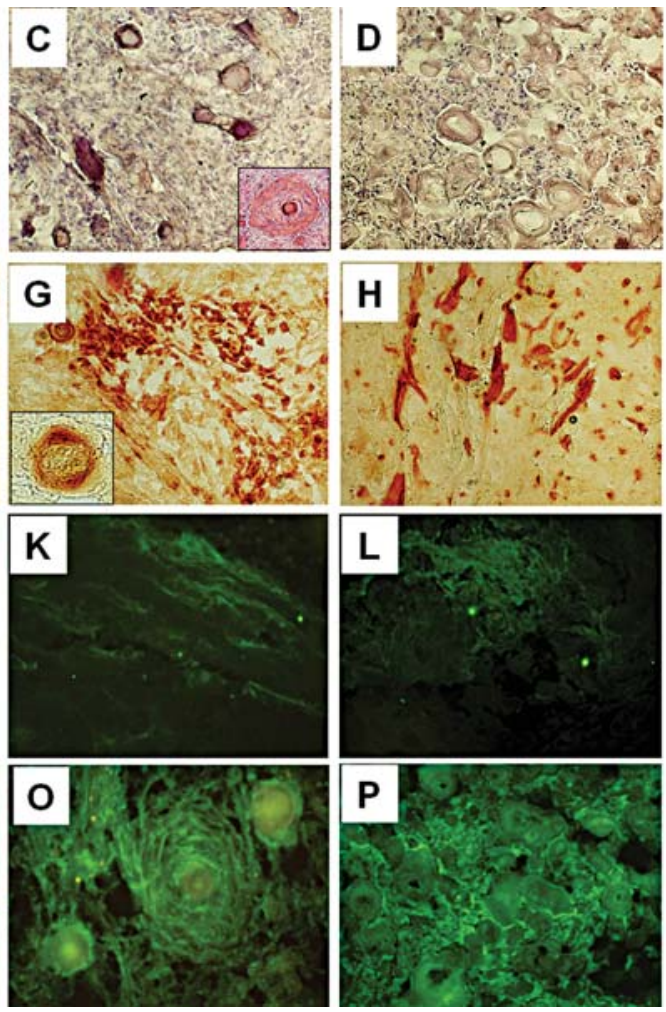
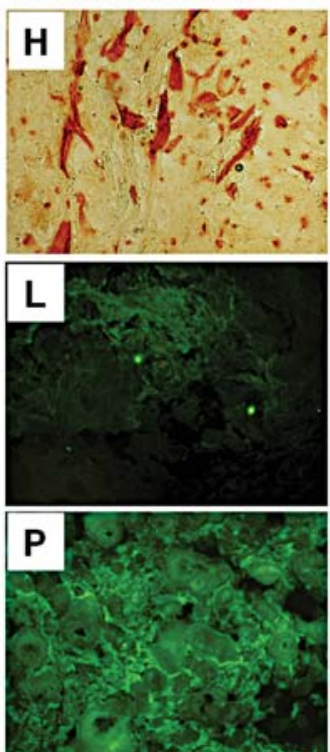

Figure 4. Histology of meningiomas WHO grade I subtypes: fibrous (A), transitional (B), psammomatous (C) and angiomatous (D). Hematoxylin-eosin staining, original magnification $\mathrm{x} 400$. Catalytic DPP-IV-like activity present in solitary or grouped cells or larger irregular patches in angiomatous and fibrous meningiomas, respectively (E and F), or trimming fibrous bundles and whorl lamellas in transitional subtypes (G and H). Low expression of DPP-IV/CD26 (I and J) and FAP $\alpha(\mathrm{K}$ and L) present mainly over the surface of fibrous bundles and whorl lamellas in fibrous and transitional subtypes, respectively. High expression of DPP8 (M and N) and DPP9 (O and P) on the surface of fibrous bundles and whorl lamellas as well as the interspaced parenchyma; original magnification $\mathrm{x} 400$.

A
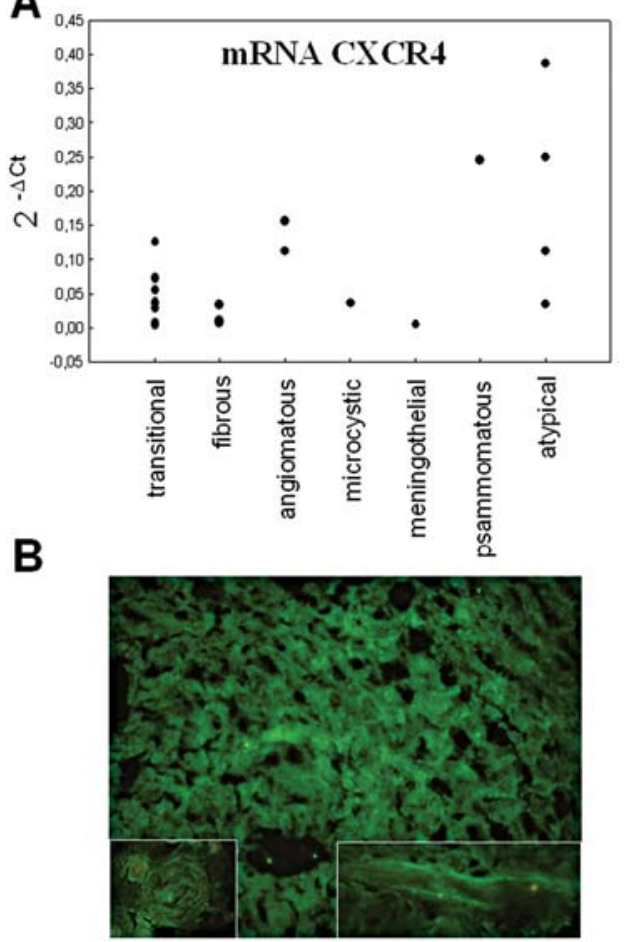

Figure 5. Expression of CXCR4 receptor determined by real-time RT-PCR normalized to human $\beta$-actin in various histological types of WHO grade I and II meningiomas (A). Immunohistochemical expression of CXCR4 over the surface of fibrous bundles and whorl lamellas; original magnification x400 (B)
CXCR4 receptor expression. The expression of CXCR4 receptor was found by real-time RT-PCR in all meningioma tissue samples, suggesting higher values in atypical grade II meningiomas ( $\mathrm{p}=0.05$, Fig. 5A). Medium or high CXCR4 protein expression was detected in 3 of 4 (75\%) atypical grade II meningiomas, while only 4 of $18(22 \%)$ benign grade I tumors demonstrated medium or high CXCR4 expression (Table III). Cytologically, the immunostaining pattern was similar to DPP-IV/CD26, except the less distinct trimming of fibrous bundles (Fig. 5B).

\section{Discussion}

This study is the first analysis of the expression and relative proportions of DASH molecules in human meningiomas. As shown here, the DPP-IV-like enzymatic activity carried by these molecules was detected in all 22 meningiomas. Compared to benign grade I meningiomas, the enzymatic activity was often higher in atypical grade II tumors, in which also the cell proliferation was higher, as detected by Ki67 immunostaining.

As revealed by real-time RT-PCR mRNA expression and immunohistochemical analysis of protein expression, both DPP8 and DPP9 are more abundantly expressed in meningiomas as compared to DPP-IV/CD26 and FAP $\alpha$. This indicates that the total DPP-IV-like enzymatic activity in these tumors is mainly attributable to DPP8 and DPP9, while the contribution of DPP-IV/CD26 and FAP $\alpha$ is relatively 
low. This is different to the human high-grade astrocytomas, in which the canonical DPP-IV/CD26 is the main contributor to the elevated DPP-IV-like enzymatic activity and is even proposed to be an indicator of grade progression of these tumors (14). This inter-tumor difference may reflect distinctions in cellular phenotypes and/or embryonic origins of astrocytic gliomas and meningiomas as well as lower degree of malignancy of the meninges-derived tumors. Putative mesodermal/mesenchymal expression pattern of a spectrum of DASH molecules, in which the expression of DPP8 and DPP9 would prevail, is suggested by immunostaining of meningocytes localized on the surface and inside the fibrous bundles and whorls rich in extra-cellular matrix secreted by these cells. Moreover, in our ongoing study, DPP8 and DPP9 have also been found to be prevalent contributors to the total DPP-IV-like enzymatic activity in normal human brain meninges. Cell differentiation changes in expression of DASH members, as another their patterndetermining factors, was observed in male reproductive organs (19). However, the role of DPP8 and DPP9 in the cell metabolism and growth is still poorly understood. In contrast to the plasma membrane-bound DPP-IV/CD26 and FAP $\alpha$, both these enzymes are cytosolic and therefore are not likely to process extracellular growth regulators. Besides their possible but unknown enzymatic intracellular functions, the enzyme activity-independent role of DPP8 and DPP9 in cellECM interactions has also been shown in cell culture (20).

Albeit low, the expression levels of DPP-IV/CD26 and FAP $\alpha$ transcripts, showed a close correlation. Proportional expression of both these paralogous molecules, products of the same gene duplication (21) was observed also in glioblastomas in situ and glioma cell cultures $(14,22)$, and their co-regulation on the transcriptional level has been suggested. This fits well with the observation in fibroblast cell cultures, in which observed DPP-IV/CD26 and FAP $\alpha$ heterodimers participate in cell migration $(23,24)$. In contrast to the high-grade astrocytomas, no difference in the expression of these two molecules between grade I and grade II meningiomas has yet been found.

It is also to be pointed out that in high-grade meningiomas, higher expression of CXCR4, the receptor of chemokine SDF- $1 \alpha$, was observed. The SDF- $1 \alpha$-mediated signaling stimulates cell proliferation and migration in a number of tumor types (25-28). This mechanism was considered to be responsible also for increased proliferation of primary meningothelial cell cultures (13). Indeed, increased expression of CXCR4 was associated with higher proliferation and the degree of cell cycle control disruption as indicated by Ki67 and 553 protein levels in CXCR4 matched samples.

In conclusion, this study is the first report on expression and tissue distribution of DASH molecules showing that DPP8 and DPP9 are the main DASH representatives in nonneuroectodermally-derived brain tumors. This is at variance with high-grade astrocytomas, in which expression of DPP-IV/ CD26 prevails.

\section{Acknowledgements}

This work was supported by grant MSMT 0021620808 and AV 0Z50110509. We are thankful to associate professor
Josef Marek from Department of Pathology, Hospital na Homolce, Prague for supervising histopathobiological analyses.

\section{References}

1. Marosi C, Hassler M, Roessler K, et al: Meningioma. Critical reviews in oncology. Hematology 67: 153-171, 2008.

2. Riemenschneider MJ, Perry A and Reifenberger G: Histological classification and molecular genetics of meningiomas. Lancet Neurol 5: 1045-1054, 2006.

3. Okada M, Miyake K, Matsumoto Y, Kawai N, Kunishio K and Nagao S: Matrix metalloproteinase-2 and matrix metalloproteinase-9 expressions correlate with the recurrence of intracranial meningiomas. J Neurooncol 66: 29-37, 2004.

4. Strojnik T, Zidanik B, Kos J and Lah TT: Cathepsins B and L are markers for clinically invasive types of meningiomas. Neurosurgery 48: 598-605, 2001.

5. Siddique K, Yanamandra N, Gujrati M, Dinh D, Rao JS and Olivero W: Expression of matrix metalloproteinases, their inhibitors, and urokinase plasminogen activator in human meningiomas. Int J Oncol 22: 289-294, 2003.

6. Goh KY, Poon WS, Chan DT and Ip CP: Tissue plasminogen activator expression in meningiomas and glioblastomas. Clin Neurol Neurosurg 107: 296-300, 2005.

7. Mentlein R: Cell-surface peptidases. Int Rev Cytol 235: 165-213, 2004.

8. Sedo A, Stremenova J, Busek P and Duke-Cohan J: Dipeptidyl peptidase-IV and related molecules: markers of malignancy? Exp Opin Med Diagn 2: 677-689, 2008.

9. Ulmer AJ, Mattern T, Feller AC, Heymann E and Flad HD: CD26 antigen is a surface dipeptidyl peptidase-IV (DPPIV) as characterized by monoclonal-antibodies clone Tii-19-4-7 and 4el1c7. Scand J Immunol 31: 429-435, 1990.

10. Tanaka T, Camerini D, Seed B, et al: Cloning and functional expression of the $\mathrm{T}$ cell activation antigen CD26. J Immunol 149: 481-486, 1992.

11. Vanhoof G, Goossens F, De Meester I, Hendriks D and Scharpe S: Proline motifs in peptides and their biological processing. FASEB J 9: 736-744, 1995.

12. Sedo A and Malik R: Dipeptidyl peptidase IV-like molecules: homologous proteins or homologous activities? Biochim Biophys Acta 1550: 107-116, 2001.

13. Bajetto A, Barbieri F, Pattarozzi A, et al: CXCR4 and SDF1 expression in human meningiomas: a proliferative role in tumoral meningothelial cells in vitro. Neurooncology 9: 3-11, 2007.

14. Stremenova J, Krepela E, Mares V, et al: Expression and enzymatic activity of dipeptidyl peptidase-IV in human astrocytic tumours are associated with tumour grade. Int J Oncol 31: 785-792, 2007.

15. Livak KJ and Schmittgen TD: Analysis of relative gene expression data using real-time quantitative PCR and the 2(T)(-Delta Delta C) method. Methods 25: 402-408, 2001.

16. Sedo A, Krepela E and Kasafirek E: A kinetic fluorometric assay of dipeptidyl peptidase IV in viable human blood mononuclear cells. Biochimie 71: 757-761, 1989.

17. Lowry OH, Rosebrough NJ, Farr AL and Randall RJ: Protein measurement with the folin phenol reagent. J Biol Chem 193: 265-275, 1951.

18. Lojda Z: Proteinases in pathology. Usefullness of histochemical methods. J Histochem Cytochem 29: 481-493, 1981

19. Dubois V, Van Ginneken C, De Cock H, et al: Enzyme activity and immunohistochemical localization of dipeptidyl peptidase 8 and 9 in male reproductive tissues. J Histochem Cytochem 57: 531-541, 2009.

20. Yu DM, Wang XM, McCaughan GW and Gorrell MD: Extraenzymatic functions of the dipeptidyl peptidase IV-related proteins DP8 and DP9 in cell adhesion, migration and apoptosis. FEBS J 273: 2447-2460, 2006.

21. Irwin DM: Ancient duplications of the human proglucagon gene. Genomics 79: 741-746, 2002.

22. Busek P, Stremenova J and Sedo A: Dipeptidyl peptidase-IV enzymatic activity bearing molecules in human brain tumorsgood or evil? Front Biosci 13: 2319-2326, 2008.

23. Rettig WJ, Garin-Chesa P, Healey JH, et al: Regulation and heteromeric structure of the fibroblast activation protein in normal and transformed cells of mesenchymal and neuroectodermal origin. Cancer Res 53: 3327-3335, 1993. 
24. Ghersi G, Dong H, Goldstein LA, et al: Regulation of fibroblast migration on collagenous matrix by a cell surface peptidase complex. J Biol Chem 277: 29231-29241, 2002.

25. Bajetto A, Barbero S, Bonavia R, et al: Stromal cell-derived factor- 1 alpha induces astrocyte proliferation through the activation of extracellular signal-regulated kinases $1 / 2$ pathway. J Neurochem 77: 1226-1236, 2001.

26. Marchesi F, Monti P, Leone BE, et al: Increased survival, proliferation, and migration in metastatic human pancreatic tumor cells expressing functional CXCR4. Cancer Res 64: 8420-8427, 2004.
27. Mizokami Y, Kajiyama H, Shibata K, Ino K, Kikkawa F and Mizutani S: Stromal cell-derived factor-1 alpha-induced cell proliferation and its possible regulation by CD26/dipeptidyl peptidase IV in endometrial adenocarcinoma. Int J Cancer 110: 652-659, 2004.

28. Zhao D, Li XP, Gao M, Zhao C, Wang JL and Wei LH: Stromal cell-derived factor 1alpha stimulates human endometrial carcinoma cell growth through the activation of both extracellular signal-regulated kinase 1/2 and Akt. Gynecol Oncol 103: 932-937, 2006. 